\title{
Pediatric Rigid Bronchoscopy for Tracheobronchial Foreign Bodies in Covid Times: Short Personal Experience
}

\author{
Suhail Amin Patigaroo ${ }^{1} \cdot$ Sajad Majid Qazi ${ }^{1} \cdot$ Rauf Ahmad $^{1} \cdot$ Manzoor A. Latoo $^{1}$ • \\ Nisar Husain Dar ${ }^{1} \cdot$ Showkat A. Showkat ${ }^{1}$ - Ahsan Ali ${ }^{1}$
}

Received: 8 August 2020/Accepted: 7 September 2020/Published online: 16 September 2020

(C) Association of Otolaryngologists of India 2020

\begin{abstract}
This case series of 5 patients of rigid bronchoscopy done for tracheobronchial foreign bodies is presented to readers to share my experience of doing rigid bronchoscopy during Covid Times from March to July 2020 specifically sharing experience on personal protection with local innovations during the procedure. Indications, intra-procedure modifications and other relevant things are also presented. The observations and experience are purely personal gained during these months and may be subjected to further research and in no way substitute the well established facts.
\end{abstract}

Keywords Covid · Rigid bronchoscopy ·

Pediatric tracheobronchial foreign bodies .

Personal protection $\cdot$ Local innovation

Suhail Amin Patigaroo

Dr_suhail_jnmc@yahoo.co.in

Sajad Majid Qazi

drsajadmajidqazi@yahoo.co.in

Rauf Ahmad

dr_rauf_sgr@yahoo.com

Manzoor A. Latoo

manzoor_latoo@yahoo.co.in

Nisar Husain Dar

darnisar@yahoo.com

Showkat A. Showkat

drshowkatent0000@gmail.com

Ahsan Ali

dralisan@gmail.com

1 Department of ENT and HNS, Government Medical College, Srinagar, J\&K, India

\section{Introduction}

Pediatric Foreign body aspirations are very common and demands early retrieval. Though the number of cases of foreign body aspirations decreased in this pandemic but unfortunately many cases still report to tertiary centers.

There are some concerns with pediatric population. About $15 \%$ of paediatric COVID positive cases are asymptomatic and $25 \%$ present with symptoms of respiratory tract infection [1]. There are also concerns regarding the high viral load of asymptomatic paediatric patients [2]. During the initial period of pandemic (March-May) chances of pediatric patients reporting for bronchoscopy to be asymptomatic carriers were less but with the increasing trend of cases from June-July and possibility of community transmission in India, the scenario at present is every pediatric patient with tracheobronchial foreign body is Covid positive unless proven otherwise. This is in keeping with guidance emerging from surgical societies and professional organizations [3].

Rigid bronchoscopy is a very high aerosol generating procedure in terms of exposure to staff for the entirety of the procedure due to a combination of aerosol-generation and prolonged gas flow. The circuit is open most of the time during bronchoscopy and this along with manipulation of tracheobronchial mucosa distributes a very high aerosol volume [4].

The procedure should be done very quickly by the most expert persons involving the minimum staff to minimize their exposure [4].

In view of False negative rate of 2-29\% in RT-PCR [5] and high percentage of children's being asymptomatic carriers; a negative pre-bronchoscopy testing whereever feasible should not make the team to lower their guard. 
There are also chances of patients with negative RTPCR in nasopharyngeal swabs to be positive at bronchial level especially since June-July as number of cases are peaking.

The Center for Disease Control and Prevention (CDC) currently recommends prioritizing negative pressure rooms and powered, air purifying respirators (PAPRs) for aerosolgenerating procedures. Since PAPR is not available everywhere, the alternatives are fit tested FFP-3 mask (N/ P-100), face shield, gown, cap, and gloves that cover the gown [6].

A minimum of fit tested N95/FFP-2 is required to do this procedure. Unfortunately Fit tested masks are not available in government setups so we need to additionally protect ourselves by creating a double layer of protection.

$\mathrm{CT}$ is mandatory if possible before rigid bronchoiscopy to be doubly sure of tracheobronchial foreign bodies [6].

This case series is aimed to highlight the need of strong personal protection and use of local innovations when standard protection is not available or was not available due to nationwide lockdown. Indications, urgency of procedure, CT, Covid testing and other relevant modifications in overall procedure are discussed.

\section{Case Series}

A total of 5 cases were done by first author since mid March 2020 till mid July 2020. The details of the case are given in Table 1.

\section{Clinical Details}

The age of patient ranged from 1 year till 2.8 years. Three were males and two were females.

CT chest was done in all cases for confirmation of foreign body. Most common finding was hyperinflation in 4 cases followed by collapse in one case. Oxygen saturation at presentation was above 90 in all except 4th case in which it was $88 \%$.

Two cases were done in beginning of pandemic in India in the month of April while one each case in May, June and July.

All cases reported within 2 days of symptoms except case 5 th which reported after 4 weeks.

\section{Covid Testing}

Covid testing was not done in case 1-4 but relative of case 4 was Covid positive. Covid testing was done in 5th patient as his history was of 4 weeks. He came out to be positive. He was admitted in isolation. His baseline biochemistry, overall clinical picture was normal. CT was showing hyperinflation and small Foreign body in right main bronchus.

In view of Covid positivity and normal parameters, it was decided to delay his bronchoscopy. The patient was monitored in hospital isolation for any distress or complications. He remained asymptomatic except for a very mild intermittent cough. On 10th days his nasopharyngeal sample came negative which was repeated again next day which also came negative. Rigid bronchoscopy was done on 15th day of admission.

\section{Procedure}

Rigid bronchoscopy was done in all cases immediately on reporting except in case 5th where it was delayed and done 2 weeks after reporting and 6 weeks after history of Foreign body aspiration.

\section{Personal Protective Equipment}

Personal protective was used in all cases but it was modified in each case as per the need and availability of PPE (Table 1).

In first case simple gown was used and no formal PPE (Fig. 1). In second case Full body gown was used but was not water proof (Fig. 2). From 3rd to 5th case full water proof Gown was used (Fig. 3).

A N-95 mask with valve was use in first two cases done in April as the same was only available in hospital.

A N-95 mask without valve was used in next two cases done in May and June.

In the last case, a full face respirator was used with a P100 filters (from3M company (Fig. 3).

A goggle was used in first three cases.

All cases were done in another layer of protection to prevent direct hitting of mask and goggles by air/aerosol jet generated by positive pressure ventilation.

In the first case an additional facial shield made of glass of scooter helmet was used (Fig. 1).

In the second case a local facial shield made from a tough polythene was used and it was tied to the head by an elastic band (Fig. 2).

In the third case a proper marketed facial shield was available in hospital in may.

In the fourth case a self made plastic box was used and from it a rectangular strip was removed for vision. This strip was covered by transparent sheet. Two additional transparent polythene sheets were attached anteriorly and posteriorly to prevent the jet of air entering the box. A small opening was made in the box posteriorly for 
Table 1 Clinical characteristics of patients and PPE used

\begin{tabular}{|c|c|c|c|c|c|c|c|c|}
\hline $\begin{array}{l}\text { Case } \\
\text { no. }\end{array}$ & Age/sex & $\begin{array}{l}\text { History of } \\
\text { typical } \\
\text { foreign } \\
\text { body } \\
\text { ingestion }\end{array}$ & $\begin{array}{l}\text { Oxygen } \\
\text { saturation } \\
\text { at } \\
\text { admission }\end{array}$ & /CT findings & Covid status & Month & $\begin{array}{l}\text { Duration } \\
\text { from history } \\
\text { to } \\
\text { bronchoscopy }\end{array}$ & Personal protection used \\
\hline 1 & 1 year $/ \mathrm{m}$ & Yes & 92 & $\begin{array}{l}\text { Hyperinflation } \\
\text { (R) }\end{array}$ & Unknown & April & 1 day & $\begin{array}{l}\text { Simple gown }+ \text { N95 Mask } \\
\text { (Valve) }+ \text { goggles }+ \text { Front } \\
\text { glass of scooter Helmet }\end{array}$ \\
\hline 2 & 1.4 years $/ \mathrm{m}$ & No & 95 & $\begin{array}{l}\text { Hyperinflation } \\
\text { (R) }\end{array}$ & Unknown & April & $6 \mathrm{~h}$ & $\begin{array}{l}\text { Full gown covering whole } \\
\text { body }+ \text { N95 Mask } \\
\text { (Valve) }+ \text { goggles }+ \text { facial } \\
\text { shield (Local made) }\end{array}$ \\
\hline 3 & 2.8 years/f & Yes & 90 & $\begin{array}{l}\text { Hyperinflation } \\
\text { (L) }\end{array}$ & Unknown & May & 1 day & $\begin{array}{l}\text { Full water proof gown covering } \\
\text { whole body }+ \text { N95 Mask } \\
\text { (without } \\
\text { Valve) }+ \text { goggles }+ \text { facial } \\
\text { shield (standard) }\end{array}$ \\
\hline 4 & 2.0 years/f & Yes & 88 & $\begin{array}{l}\text { Partial } \\
\quad \text { Collapse (R) }\end{array}$ & $\begin{array}{l}\text { Unknown but } \\
\text { relative positive }\end{array}$ & June & 2 days & $\begin{array}{l}\text { Full water proof gown covering } \\
\text { whole body }+ \text { N95 Mask } \\
\text { (without Valve) }+ \text { self made } \\
\text { box (with oxygen) }\end{array}$ \\
\hline 5 & 1.4 years $/ \mathrm{m}$ & Yes & 95 & $\begin{array}{l}\text { Hyperinflation } \\
\text { (R) }\end{array}$ & $\begin{array}{l}\text { Positive by RTPCR } \\
\text { nasopharyngeal } \\
\text { swab } 2 \text { weeks } \\
\text { before } \\
\text { bronchoscopy }\end{array}$ & July & 6 weeks & $\begin{array}{l}\text { Full water proof gown }+ \text { full } \\
\text { face respirator with P100 } \\
\text { filters }+ \text { additional hood. } \\
\text { Valve covered with N-95 }\end{array}$ \\
\hline
\end{tabular}

Table 2 Modifications done during Bronchoscopy

\begin{tabular}{|c|c|c|c|c|c|}
\hline $\begin{array}{l}\text { Case } \\
\text { no. }\end{array}$ & $\begin{array}{l}\text { Bronchoscope inserted after closing } \\
\text { the working channel by a glass cap } \\
\text { and additionally covering by a } \\
\text { transparent polythene sheet covering } \\
\text { the mouth, nose and anesthesia and } \\
\text { fiberoptic light connector }\end{array}$ & $\begin{array}{l}\text { Positive pressure ventilation halted } \\
\text { completely, forceps introduced and } \\
\text { FB removed. As saturation dropped, } \\
\text { instruments removed glass cap re } \\
\text { fitted and pt ventilated. The cycle } \\
\text { repeated till all foreign body was } \\
\text { removed }\end{array}$ & $\begin{array}{l}\text { Positive pressure ventilation } \\
\text { could not be completely halted } \\
\text { while foreign body was removed } \\
\text { as saturation dropped while } \\
\text { removing }\end{array}$ & $\begin{array}{l}\text { Positive } \\
\text { pressure } \\
\text { ventilation } \\
\text { was not } \\
\text { halted at all }\end{array}$ & $\begin{array}{l}\text { Use of } \\
\text { telescope, } \\
\text { telescopic } \\
\text { forceps } \\
\text { and }\end{array}$ \\
\hline 1 & $\mathrm{x}$ & $\mathrm{x}$ & $\mathrm{x}$ & $\mathrm{y}$ & $\mathrm{x}$ \\
\hline 2 & $\mathrm{x}$ & $\mathrm{x}$ & $\mathrm{x}$ & $\mathrm{y}$ & $\mathrm{x}$ \\
\hline 3 & $\mathrm{x}$ & $\mathrm{y}$ & $\mathrm{x}$ & $\mathrm{x}$ & $\mathrm{x}$ \\
\hline 4 & $\mathrm{y}$ & $\mathrm{x}$ & $\mathrm{y}$ & $\mathrm{x}$ & $\mathrm{x}$ \\
\hline 5 & $\mathrm{y}$ & $\mathrm{y}$ & $\mathrm{x}$ & $\mathrm{x}$ & $\mathrm{x}$ \\
\hline
\end{tabular}

y maneuver done

$\mathrm{x}$ maneuver not done

aeration. A small oxygen pipe was inserted into the box for oxygenation (Fig. 4).

In the last case additional hood was used with a small hole at the top (Fig. 3).

\section{Staff, Instruments Used and Preoperative Theatre Preparations}

Only well trained bronchoscopist (First author) and one assistant carried the procedure. A well trained anesthesiologist and assistant gave general anesthesia. A briefing of procedure was given to assistants and anesthesiologist in advance. Anticipated difficulties were discussed. A sign language was explained to assistant and anesthesiologist so that no difficulty is faced intraoperatively as Facial shields, masks and respirators decrease hearing and hamper communication.

All instruments were checked beforehand. Patient was not shifted to theatre unless everything relevant was checked and discussed. 
Fig. 1 Showing simple gown and head cap used in first bronchoscopy. Also shows glass of scooter helmet used in first bronchoscopy as an additional protection. Also see that surgeon is very close to jet of air/aerosols while doing bronchoscopy
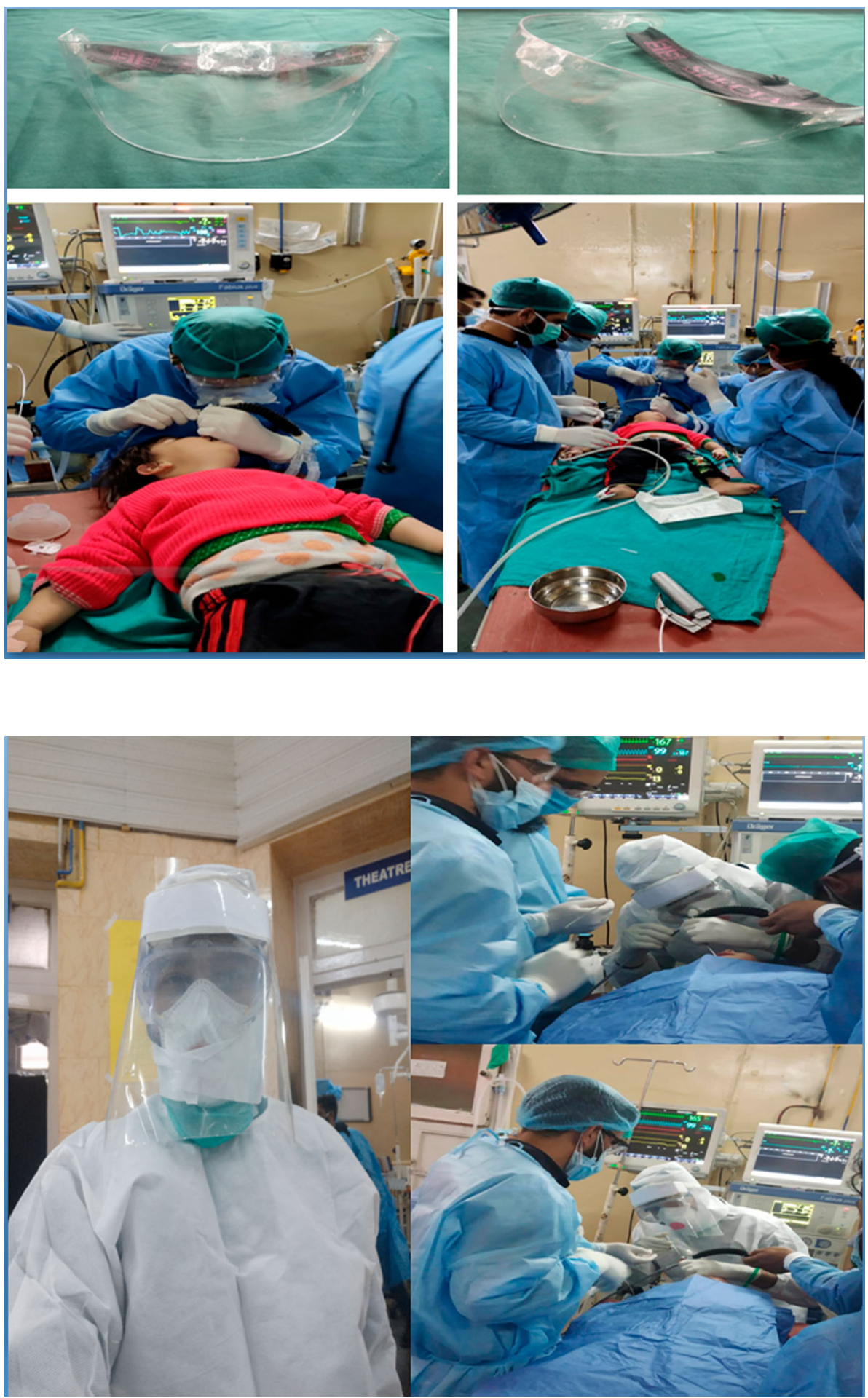

Fig. 2 Showing Full gown but not water proof and local made facial shield as an additional protection used in second bronchoscopy. Also see that surgeon is very close to jet of air/aerosols while doing bronchoscopy
Windows of operation theatre were kept open. and only 5 people in theatre (4 actively involved and 5 th one for some help) was allowed.

Selected Bronchoscope of Karl Storz as per age was covered in case 4 th and case 5 th by a polythene sheet (Fig. 5) and only working channel of bronchoscope was spared so as to cover whole face, neck, shoulders, anesthesia circuit and fiberoptic light source cable attached to bronchoscope (Fig. 5).

\section{Intraoperative Modification}

Patient were completely paralyzed and well preoxygenated. 
Fig. 3 Showing Full water proof gown used in 3-5 bronchoscopy. Full face respirator with P100 filters (red) was used in 5th bronchoscopy. Also see that exhalation port of respirator at center is covered by white $\mathrm{N}-95$ mask. The right side shows additional hood with hole at top (to decrease fogging) used to cover respirator
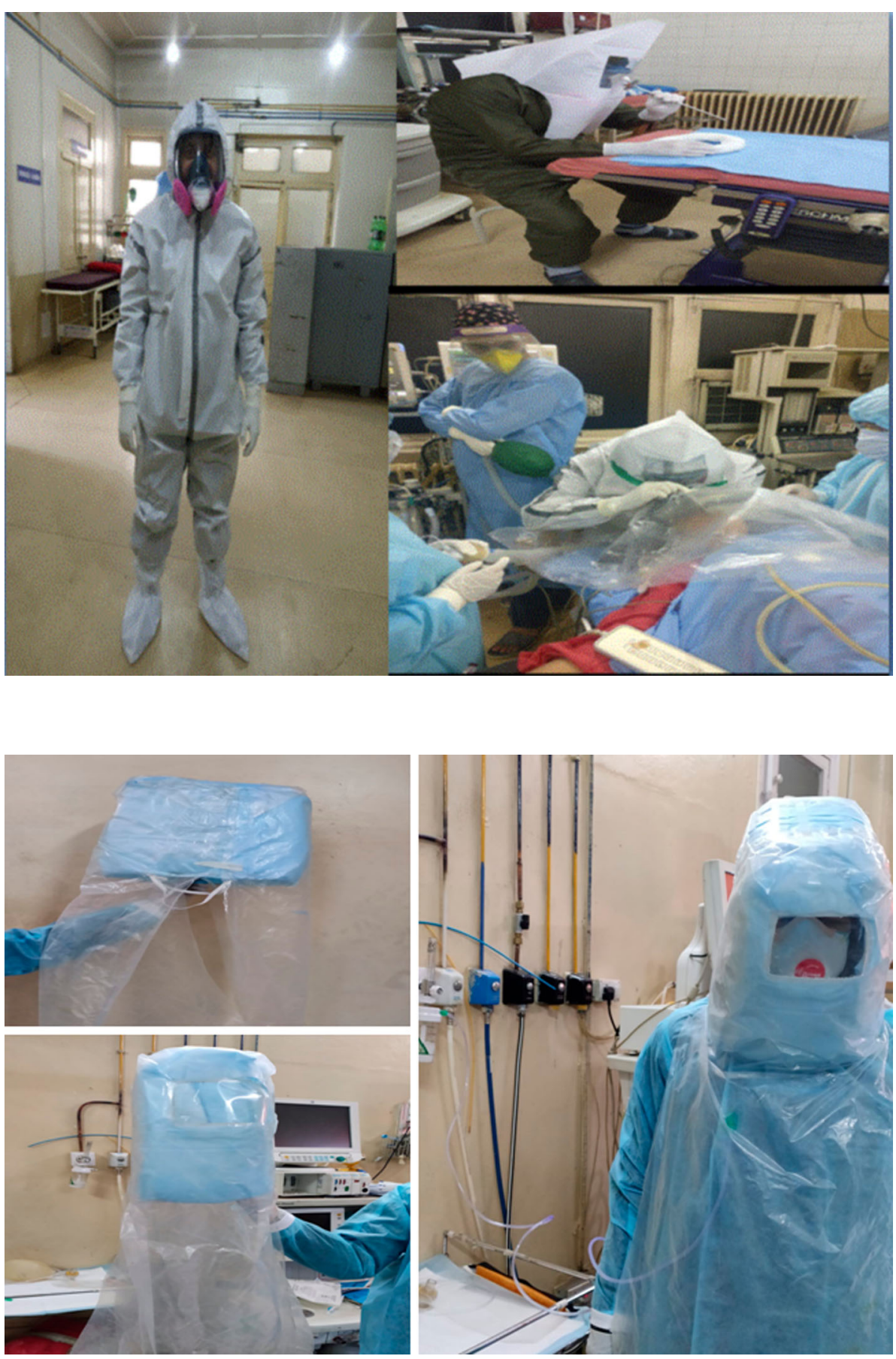

Fig. 4 Shows a self made plastic box with two transparent polythene sheets attached anteriorly and posteriorly. A small window covered with thick transparent polythene is created for vision. Oxygen pipe entering the box can be seen
Very quickly the bronchoscope was inserted to which polythene sheet was attached in case 4th and 5th. In continuity foreign body was visualized and initial attempts of removal were done.

In case 1-2 no attempt to halt positive pressure ventilation was done. No positive pressure ventilation at all was given initially and while forceps were in working channel in case 3rd and 5th and as soon as oxygen saturation dropped below $85 \%$ the anesthesiologist signaled and immediately forceps were removed from working channel. Glass cap was used to cover the bronchoscope and pt were ventilated (Table 2).

During ventilation the bronchoscopist left the operating chair for brief time and as soon as saturation again went up above 90 percent, glass cap was again removed and forceps reinserted. This cycle was repeated till whole FB was removed.

In case 4 , intermittent positive pressure ventilation was given as saturation dropped quickly when forceps were inside the working channel. 
Fig. 5 A transparent polythene sheet is attached to bronchoscope so that the sheet covers face, neck, shoulders and anesthetic circuit and Fiberoptic cable attachment. Also seen is a glass cap that is attached to working channel opening for closing the circuit when saturation starts dropping

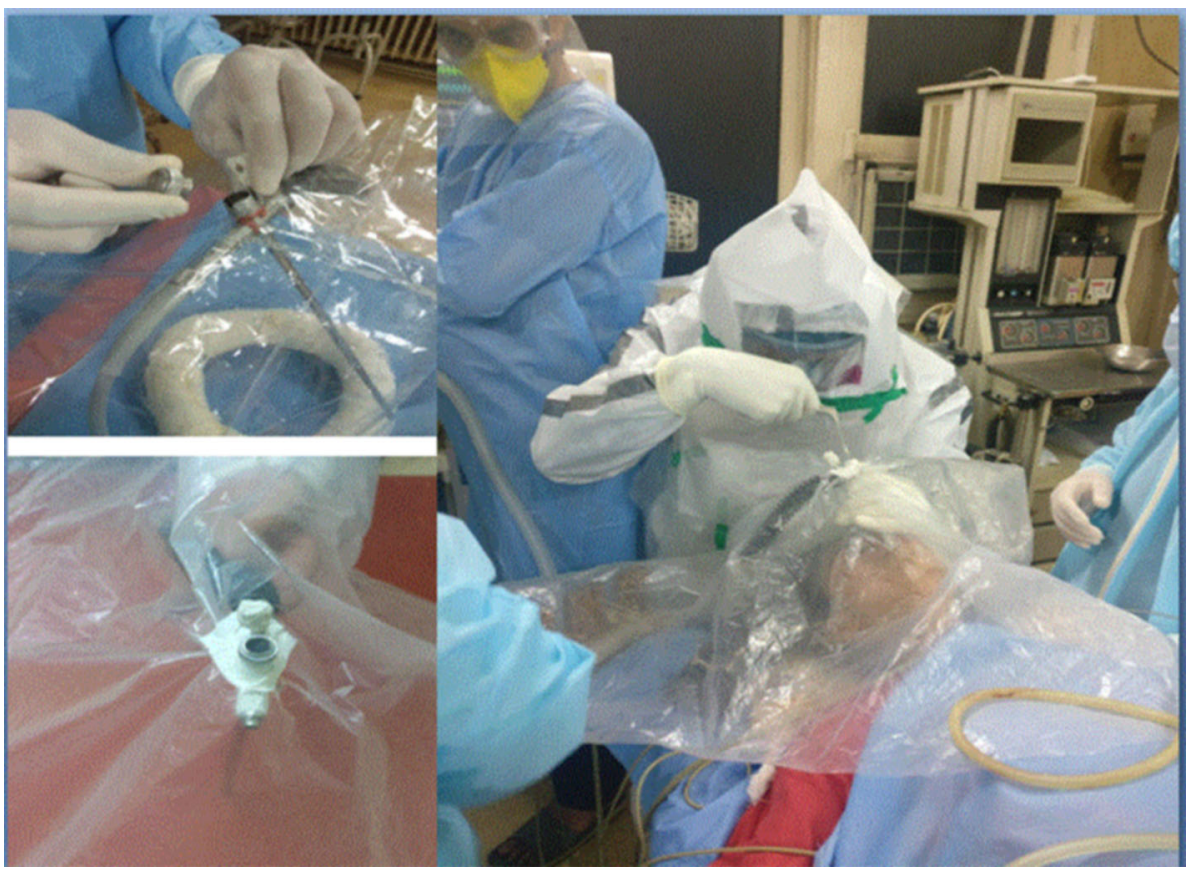

The number of times forceps were inserted to remove foreign body was two times in case 1 , three times in case 2,3,5 and 4 times in case 4 .

Procedure was tried to be completed as soon as possible.

\section{Nature of FBs}

All retrieved foreign bodies were vegetative in nature. Ground nut in first case, Cashew nut in second, green peas in third, a piece of rajma in fourth. The case 5th had small piece of the cover of apple.

\section{Discussion}

Tracheobronchial foreign body aspirations did show a decreasing trend since pandemic but tertiary hospitals like ours still encounter these cases. These foreign bodies usually demand urgent removal in most of the cases especially when the patient is in distress or is expected to go in distress.

Rigid bronchoscopy for such cases carries probably highest risk of aerosol generation. Since the surgeon is very close to bronchoscope (Figs. 1, 2), the risk of transmission of Covid is highest to surgeon followed by other team members.

History of Foreign body aspiration was clear in all of our cases and four of them reported to hospital within 2 days while 5th case reported after 1 month. All of these patients were mildly symptomatic at presentation with no respiratory distress and saturation of 4 cases was above 90\% while case 4th had saturation below $90 \%$.

Preoperative covid testing was not done in cases 1-4.

At present, there is variability across institutions with respect to access to testing, time taken for testing, and reliability of results including false negative rates that at some institutions may be as high as 30-40\% [7].

Pediatric patients are asymptomatic carriers especially in our scenario when community transmission is suspected. Besides this many people have noted that the nucleic acid of SARS CoV-2 could be detected from Broncheoalveolar lavage (BAL) samples of critically ill patients with COVID-19 pneumonia while not from the upper respiratory tract specimens of some patients [8-10].

The judgment of clinical condition of patient by bronchoscopist, type of foreign body ingested, prevalence of Covid-19 in the community from which patient belong and all the above variables will influence whether a pre-bronchoscopy Covid testing should be done or not.

As already highlighted a negative test is insufficient to negate the need for intraoperative precautions but it may decrease the need for pre- and post-operative airborne isolation, thereby preserving limited PPE [6].

Covid-19 testing was done in 5th patient as he had history of 1 month and was from red zone. It came out to be positive. The bronchoscopy was deferred for 2 weeks.

The question is in case wherever Covid testing (wherever feasible) is done prebronchoscopy and it turns positive, should we wait or do immediate intervention and what benefit we will get from waiting. The role and opinion of senior most bronchoscopist and pulmonary pediatrician is 
very important in such case. One has to weigh the risk between waiting and doing the procedure immediately. The review of the available current literature on infectivity will guide.

Over the course of the infection, the virus has been identified in respiratory tract specimens 1-2 days before the onset of symptoms and it can persist for 7-12 days in moderate cases and up to 2 weeks in severe cases [11]. Viral RNA concentrations peak within first 5 days after onset of symptoms and decrease slowly below the threshold where replication competent virus can be isolated with rising antibody concentration and binding of these antibodies to the virus is expected to reduce the risk of virus transmission [12-14]. In the feces and lower respiratory tract this viral load seems to peak in the second week of illness [15]. Three studies of patients with undisclosed or variable degree of illness showed an inability to culture virus after days 7-9 of symptom onset [14, 16].

Taking available literature into consideration, it is wise to wait for rigid bronchoscopy for at least 2 weeks after positive Covid testing but as already mentioned a senior bronchoscopists and a pulmonary pediatrician has to give nod for waiting. During this waiting time patient should be observed in isolation ward.

With this available literature in mind and pro and cons into consideration rigid bronchoscopy in our fifth patient was deferred for 2 weeks but he was observed in isolation ward.

CT findings in 4 cases was hyperinflation while in 4 th case it was collapse (R).

$\mathrm{CT}$ imaging has routinely been used as a first investigation in suspected airway foreign even prior to the COVID-19 pandemic [17]. Sensitivity is near $100 \%$ but specificity is approximately $70 \%$ [18]. To minimize negative bronchoscopies and its associated risks of transmission during the current COVID-19 pandemic, low-dose, noncontrast computerized tomography (CT) is necessary to confirm the presence of a foreign body if the patient is an appropriate candidate and does not require general anesthesia to obtain the imaging [6]. A patient with negative CT has no urgency for rigid bronchoscopy even if foreign body suspicion is very high in this era of Covid. Conversely a rigid bronchoscopy should be done straight away in a clinically unstable patient with high suspicion of foreign body with full possible and available airborne precautions.

A proper PPE is absolutely necessary for procedure and this statement carries more weight during this time when community transmission is suspected in India. Every child needs to be taken as Covid positive unless proven otherwise and accordingly all available PPE should be used properly even if it means protecting yourself by local innovations as done by first author in this pandemic.
For airway protection a PAPR is ideal but not available everywhere. The second option is fit tested FFP-3/N(P) 100 mask and the minimum requirement is fit tested N95 [6].

Since the available masks are not fit tested everywhere, every effort should be made to stop jet of air/aerosol directly striking the mask and goggles of bronchoscopist by using additional shield especially when the case is done without telescopic forceps and monitor as in our series. The surgeon should innovate or in local language do JUGAD to protect himself/herself.

A proper donning and especially doffing method should be adopted. Doffing of PPE is high risk for transmission of aerosolized material and poor technique has been associated with increased COVID infection rates in healthcare workers $[19,20]$. Team members should supervise each other while doffing and ample time should be given for it in correct sequence.

During the initial days of pandemic recommended PPE was not available. The first case was done by first author with a N-95 mask with valve, simple gown and additional shield made from glass of scooter helmet (Fig. 1). In the second case whole body suit was available in April but was not water proof. N-95 mask with valve was used with additional local made facial shield (Fig. 2). The third case was done in Full water proof gown with N-95 Mask without valve and marketed facial shield. The fourth case was done in a patient in June when covid patients were increasing in our state and since patients relative was positive so accordingly a self made box was used in addition to N-95 mask without valve (Fig. 4).

The fifth case was done in a patient after 14 days of RTPCR Positivity by wearing a full face respirator with P100 filters with additional hood (Fig. 3). The Exhalation valve was covered by N-95 mask to prevent any aerosols which forcefully strike the mask entering into the mask via exhalation port.

As can be noted first author modified PPE as and when better protection was needed by doing local innovations as these procedures cannot be always denied on the pretext of non availability of ideal protection. One common problem encountered was fogging of eye goggles and for this author used a leucoplast tape over the superior border of mask thereby preventing air leak into goggles. The other options are ventilation ports in googles, anti fog solutions and antimist glasses, The glass in the mask used in fifth case was antimist.

Procedures should be performed in a negative pressure room but hardly available anywhere in India. We opened all windows of our theatre and kept only 5 persons in theatre (Two from surgery side, two from anesthesiology side and one additional for any help).

Discussion and planning with all involved personnel before the procedure is essential to ensure the surgery runs 
smoothly and exposure risks are limited. All potentially necessary instruments are prepared and checked at the beginning of the case [6]. It is difficult to communicate with others while wearing PPE for bronchoscopy so preoperatively a clear sign language should be communicated to all members.

Some authors recommend that prior to initiating rigid bronchoscopy which inherently increases droplet spread, diagnostic and potentially therapeutic flexible bronchoscopy may be performed through an LMA or ETT [6]. Flexible bronchoscopy may help confirm the presence the location of any potential foreign body and if no foreign body is identified, the rigid bronchoscopy portion can be aborted and aerosolization minimized [6]. We feel this is not needed and instead recommend CT scans preoperatively.

We did not use telescopic forceps and monitors as they are not functional at present in our department but it is strongly recommended utilizing telescopic forceps/monitors during bronchoscopy to maximize the distance between the surgeon's face and the patient's airway so as to decrease risk of exposure to direct aerosols [6].

During rigid bronchoscopy aerosols come out from trachea and bronchi both along the sides of bronchoscope and via working channel. There are full chances of these aerosols striking the masks and goggle especially when doing it without telescopic forceps and monitors. So additional protection is necessary to prevent this jet of air/ aerosols which comes out during positive pressure ventilation to strike goggles and mask. The additional protection in first three cases was only facial shield while in 4 th case it was box.

In 4th and 5th cases bronchoscope was covered by a polythene sheet which covered the face, neck, shoulders, anesthesia circuit and fibre optic cable attachment as another additional protection (Fig. 5). The use of polythene sheet in different designs than ours have too been advocated by other authors $[6,21]$ but the way they have described to use such sheets/surgical tents is cumbersome to use especially in emergency situations of tracheobronchial foreign bodies.

The exhalation port should be covered and if possible masks without exhalation port should be used. In normal circumstances during pre-covid times, almost every time anesthesia gases were inhaled by first author routinely.

Positive pressure ventilation was not halted at all during bronchoscopy in first two cases as the same concept did not came to our mind.

In case 3rd and 5th Positive pressure ventilation was halted completely while forceps were removing foreign body. Once oxygen saturation started dropping below $85 \%$, glass cap of bronchoscope was used to cover the working channel. This cycle was repeated till all foreign body was removed. In case 4th positive pressure ventilation could not be completely halted while forceps were in the working channel removing foreign body as oxygen saturation dropped. Positive pressure was intermittently given.

In all possible way positive pressure ventilation should be halted while forceps are in working channel and glass cap is not covering working channel but this is not always possible especially when preoperative saturation is less and bronchoscopy is not performed by trained persons as seen in case no 4.

Every effort should be made to ventilate properly before inserting bronchoscope. Foreign body should be tried to remove initially in first attempt while bronchoscope is inserted but that is not always possible especially in vegetative foreign body that comes in piece meal.

Since the lockdown is lifted from India in a phase wise manner and also the number of cases are increasing day by day, it is extremely important to equip the department with ideal PPE like PAPR/FFP-3 MASKS and telescopic forceps and monitors.

All personnel's involved in bronchoscopy of positive patient should isolate themselves and if possible isolation should be done in pts with unknown or known negative status. So far our team is asymptomatic and tested negative even month after the last foreign body removal.

\section{Conclusion}

Rigid bronchoscopy for tracheobronchial foreign bodies is the highest aerosol generating procedure. The risk of getting infected is very high if proper precautions are not taken. Doing this procedure without adequate protection may mimic suicide. All patients should be taken as covid positive even if RTPCR of nasopharyngeal swab where ever done pre-operatively is negative and accordingly adequate precautions should be taken. The ideal protection and instruments may not be always available and in such cases local innovations should be done to the best of capacity to minimize exposure as far as possible. The help of a local engineering friend in innovations can prove fruitfull. Double layer of protection to minimize jet of air/ aerosol striking the mask/goggles should always be used. Persons entrusted with such procedures needs to raise their guards to highest possible level.

Funding The research did not receive any fundings.

Availability of data and material This is just observational study highlighting what authors used as a Personal protection. 


\section{Compliance with the ethical standards}

Conflict of interest The authors declare that they have no competing interests.

Consent to participate Proper consent taken from patient whenever needed.

\section{References}

1. Lu X, Zhang L, Du H, Zhang J, Li YY, Qu J et al (2020) SARSCoV-2 infection in children. N Engl J Med. https://doi.org/ 10.1056/nejmc2005073

2. Kam K-Q, Yung CF, Cui L, Pin RLT, Mak TM, Maiwald M et al (2019) A well infant with coronavirus disease (COVID-19) with high viral load. Clin Infect Dis Off Publ Infect Dis Soc Am 361(2020):1701. https://doi.org/10.1093/cid/ciaa201

3. Magennis P, Kumar N (2020) British Association of Oral \& Maxilofacial Surgeons \& ENTUK: guidance PPE for patients with emergency oropharyngeal and nasopharyngeal conditions whose COVID Status is unknown

4. Frauenfeldera C, Butlera C, Hartley B, Cochranea L, Jephsona C, Nasha R et al (2020) Practical insights for paediatric otolaryngology surgical cases and performing microlaryngobronchoscopy during the COVID-19 pandemic. Int J Pediatric Otorhinolaryngol. https://doi.org/10.1016/j.ijporl.2020.110030

5. Arevalo-Rodriguez I, Buitrago-Garcia D, Simancas-Racines D (2020) False-negative results of initial RT-PCR assays for COVID-19: a systematic review. medRxiv. Jan 1

6. Francoma CR, Javiab LR, Wolterc NE, Leed GS, Winea T et al (2020) Pediatric laryngoscopy and bronchoscopy during the COVID-19 pandemic: a four-center collaborative protocol to improve safety with perioperative management strategies and creation of a surgical tent with disposable drapes. Int J Pediatric Otorhinolaryngol. https://doi.org/10.1016/j.ijporl.2020.110059

7. Wang W, Xu Y, Gao R, Lu R, Han K, Wu G, Tan W (2020) Detection of SARS-CoV-2 in different types of clinical specimens. JAMA—J Am Med Assoc. https://doi.org/10.1001/jama. 2020.3786

8. Yang Y, Minghui Y, Chenguang S, Fuxiang W, Jing Y, Jinxiu L et al (2020) Evaluating the accuracy of different respiratory specimens in the laboratory diagnosis and monitoring the viral shedding of 2019-nCoV infections. Medrxiv. https://doi.org/ 10.1101/2020.02.11.2002

9. Zhang P, Cai Z, Wu W, Peng L, Li Y, Chen C et al (2020) The novel coronavirus (COVID-19) pneumonia with negative detection of viral ribonucleic acid from nasopharyngeal swabs: a case report. BMC Infect Dis 20:317. https://doi.org/10.1186/s12879020-05045-Z

10. Gualanoa G, Mussoa M, Mostia S, Mencarinia P, Mastrobattistaa A, Pareoa $C$ et al (2020) Usefulness of bronchoalveolar lavage in the management of patients presenting with lung infiltrates and suspect COVID-19-associated pneumonia: a case report. Int $\mathbf{J}$ Infect Dis. https://doi.org/10.1016/j.ijid.2020.05.027

11. Wang Y, Wang Y, Chen Y, Qin Q (2020) Unique epidemiological and clinical features of the emerging 2019 novel coronavirus pneumonia (COVID-19) implicate special control measures. J Med Virol. https://doi.org/10.1002/jmv.25748

12. Wolfel R, Corman VM, Guggermos W et al (2020) Virological assessment of hospitalized patients with COVID-19. Nature 581:465-469

13. Atkinson B, Petersen E (2020) SARS-CoV-2 shedding and infectivity. Lancet 395(10233):1339-1340

14. Criteria for releasing COVID-19 patients from isolation. Scientific brief .17june 2020.WHO

15. Weiss A, Jellingsoe M, Sommer MOA (2020) Spatial and temporal dynamics of SARS-CoV-2 in COVID-19 patients: a systemic review. Preprint_ MEDRXIV. https://doi.org/10.1101/ 2020.05.21.20108605

16. Bullard J, Dusk K, Funk D et al (2020) Predecting infectious SARS-CoV2 from diagnostic samples. Clin Infect Dis. https://doi.org/10.1093/cid/ciaa638

17. Pitiot V, Grall M, Ploin D, Truy E, Ayari Khalfallah S (2017) The use of CT-scan in foreign body aspiration in children: a 6 years' experience. Int $\mathrm{J}$ Pediatr Otorhinolaryngol 102:169-173. https://doi.org/10.1016/j.ijporl.2017.08.036

18. Bluestone and stools pediatric Otolaryngology (2014) Foreign bodies of larynx, trachea and bronchi, 3rd edition. Peoples Medical Publishing house. Volume 2(96), p 1615

19. Tran K, Cimon K, Severn M, Pessoa-Silva CL, Conly J (2012) Aerosol generating procedures and risk of transmission of acute respiratory infections to healthcare workers: a systematic review. PLoS ONE 7:e35797. https://doi.org/10.1371/journal.pone. 0035797

20. Cheung JC-H, Ho LT, Cheng JV, Cham EYK, Lam KN (2020) Staff safety during emergency airway management for COVID19 in Hong Kong. Lancet Respir Med. https://doi.org/10.1016/ s2213-2600(20)30084-9

21. Pollaers K, Herbert H, Vijayasekaran S (2020) Pediatric microlaryngoscopy and bronchoscopy in the COVID-19 Era. JAMA Otolaryngol Head Neck Surg 146(7):608-612. https://doi.org/ 10.1001/jamaoto.2020.1191

Publisher's Note Springer Nature remains neutral with regard to jurisdictional claims in published maps and institutional affiliations. 